\title{
Atividades grupais reflexivas com estudantes de Medicina
}

\section{Reflective group activities with medical students}

\section{PALAVRAS-CHAVE \\ - Estudantes de medicina. \\ - Desempenho de Papéis. \\ - Educação médica.}

\section{KEY WORDS \\ - Students, Medical. \\ - Role-Playing. \\ - Education, Medical.}

\begin{abstract}
R E S U M O
As práticas grupais desenvolvidas junto a estudantes de Medicina assumem uma característica de técnica de ensino, oferecendo-lhes um espaço para a reflexão crítica sobre o desenvolvimento de seu papel profissional. Assim, como referencial teórico para o trabalho em grupos, destacamos o sociodrama educacional, caracterizado como uma linha de pesquisa-ação em Psicologia Educacional. O objetivo deste estudo foi avaliar os efeitos de atividades grupais reflexivas com referencial sociodramático desenvolvidas com estudantes de Medicina de uma universidade pública. Participaram dez estudantes do segundo ao quarto anos, previamente selecionados. As atividades foram conduzidas em nove reuniões semanais e finalizadas com um role-playing, cujo tema foi o ingresso no curso médico. A experiência foi avaliada como positiva para os estudantes, sendo destacados: os benefícios do compartilhar em grupo as dificuldades da formação médica; a integração de alunos de anos diferentes; o favorecimento de vínculos positivos entre os integrantes; a experiência vivencial de se colocar no lugar do outro por meio do role-playing e de possibilitar maior reflexão crítica sobre o desenvolvimento do papel profissional.
\end{abstract}

\section{A B S T R A C T}

Group activities with medical students represent a key teaching technique, offering them a space for critical reflection on the development of their professional role. Thus, as a theoretical reference for group work, we highlight educational sociodrama, a line of action-based research in Educational Psychology. The aim of this study was to evaluate the effects of reflective group activities with sociodrama as the reference, developed with medical students in a public university. Ten previously selected second-year to fourth-year students participated. The activities were held in nine weekly meetings and concluded with a role-playing exercise, the theme of which was enrollment in medical school. The students rated the exercise positively, highlighting the benefits of sharing their difficulties in medical training with the group, integration of students from different classes, fostering positive links between the members, the experience of putting oneself in another's place through role-playing, and opportunity for more critical reflection on the development of their professional role. 


\section{INTRODUÇÃO}

\section{As práticas grupais em educação médica}

O cotidiano acadêmico de estudantes de Medicina propicia o contato e a vivência com ambientes educacionais diversos. Nesses espaços, pode ocorrer a educação informal distorcida, muitas vezes, da real prática profissional. Sendo assim, identifica-se a necessidade crescente de intervenções educacionais que possam minimizar o conflito às vezes vivido entre a dicotomia teoria e prática durante a graduação $\mathrm{O}^{1,2}$.

Os novos cenários de aprendizagem preconizados atualmente pelas Diretrizes Curriculares Nacionais para os cursos médicos propõem, entre algumas questões, a formação de um profissional com posturas críticas e reflexivas frente a sua práti$\mathrm{ca}^{3}$. Muitas são as estratégias no contexto do ensino nas escolas médicas que procuram transformar seus projetos político-pedagógicos em propostas menos tradicionalistas, permitindo que o estudante seja sujeito de sua aprendizagem ${ }^{4}$.

Diante de um novo panorama da educação médica, identificamos a necessidade da inserção de ferramentas educacionais apropriadas que possam contribuir para desenvolver atitudes socialmente aceitáveis e adequadas à prática médica. $\mathrm{O}$ ensino médico atualmente revê seus espaços institucionais, criando contextos apropriados de reflexão e construção crítica para o aprendizado do papel profissional.

As atividades grupais durante a formação médica, de certa forma, tentam contribuir para o preencher as lacunas existentes nos cenários de aprendizagem, que carecem de estratégias que ajudem o estudante a "processar" suas experiências acadêmicas de forma construtiva e crítica. Entendemos, dessa forma, que estas atividades podem assumir uma característica de técnica de ensino, independentemente do referencial teórico adotado ${ }^{5,6}$. Elas têm sido destacadas como meios eficazes de auxiliar alunos e professores no processo de transformação e construção de novas realidades educacionais na trajetória do curso médico.

No ensino médico encontramos diversas experiências com ênfase no trabalho em grupos. Estas atividades, em sua maioria, estão associadas ao contexto de ensino-aprendizagem, como a atividade em pequenos grupos, cuja ênfase é a aprendizagem baseada em problemas (PBL) ${ }^{7}$. Também são valorizadas as experiências com estudantes que permitam a construção de uma identidade médica, ou ainda o desenvolvimento de habilidades e atitudes no aprendizado da relação médico-paciente, como os Grupos Balint e Grupos de Reflexão ${ }^{5,6}$.

Em relação aos grupos Balint, de referencial psicanalítico, seu objetivo é proporcionar aos profissionais e estudantes o entendimento e a superação de dificuldades encontradas na prática mé- dica ${ }^{5,6}$. Um possível efeito dessa atividade grupal com estudantes ou profissionais médicos é questionar não apenas as identificações adquiridas durante a formação médica, mas também as consequências destas sobre a atitude do médico em sua prática ${ }^{8}$.

Os grupos com estudantes de Medicina podem ainda auxiliar na resolução de ansiedades ligadas a processos complexos de aprendizagem em que o estudante é estimulado a vivenciar seu processo de ensino-aprendizado inserido num movimento de ação-reflexão-ação desde o início do curso ${ }^{7,9}$.

Ainda que os grupos com ênfase no ensino possam ter como foco principal a aprendizagem, acreditamos que seus benefícios possam atingir áreas mais amplas das relações humanas e de seus problemas. Dessa forma, salientamos que, na formação médica, os grupos reflexivos não visam ao tratamento psicoterapêutico, mas são dirigidos ao aprendizado de tensões que podem ser originadas dos processos de formação acadêmica que envolvem componentes do indivíduo, da instituição e de toda a convivência institucional originada desse processo ${ }^{9}$.

As diferenças entre os grupos que serão desenvolvidos nos contextos educacionais divergem apenas em relação as suas finalidades e objetivos. Os grupos operativos são desenvolvidos nos campos de ensino-aprendizagem, em contextos institucionais, comunitários e terapêuticos. Os grupos psicoterápicos se destinam à aquisição de insight e dos aspectos inconscientes dos indivíduos e da totalidade grupal ${ }^{10}$.

Durante sua trajetória acadêmica, os estudantes de Medicina encontram obstáculos relacionados a todo um aparato sóciocultural-histórico da profissão médica e, dessa forma, muitas vezes, precisam aprender a conviver com a dicotomia existente entre suas individualidades e o contexto grupal, que possui suas normas, regras e valores. Ao mesmo tempo em que é estimulado a adquirir conhecimentos, o aluno também tem que aprender a administrar seus sentimentos de impotência, medos e inseguranças, quando, por exemplo, é iniciado na "aprendizagem das relações humanas". Os primeiros relacionamentos com os professores e com os colegas demonstram que as relações interpessoais ao longo de sua formação serão sempre protagonistas de seu processo de amadurecimento.

À medida que o curso evolui, torna-se evidente para o estudante que agora não é necessário apenas o desenvolvimento de habilidades cognitivas, mas também o "pensar" na sua prática, em como desenvolver suas habilidades clínicas e de interação com seus pacientes e pares.

A inserção nesse cenário de aprendizagem cada vez mais complexo apresenta ao estudante uma multiplicidade de elementos que passam a compor sua prática, elementos estes pro- 
venientes do próprio aluno, dos pacientes, do sistema de saúde vigente, do contexto social, cultural, científico, técnico e organizacional em que se insere a prática médica ${ }^{11}$.

Independentemente de quais objetivos estejam sendo seguidos (educacionais, reflexivos ou terapêuticos) e até mesmo de quais referenciais teóricos estejam sendo adotados, nota-se que as atividades grupais com estudantes de Medicina lhes oferecem uma variedade de benefícios. Assim, estas atividades podem subsidiar os contextos educacionais quanto às dificuldades que possam estar impedindo os grupos de realizar suas "tarefas" e de estabelecer relações interpessoais que favoreçam o aprendizado no contexto acadêmico ${ }^{5,6}$.

\section{Atividade grupal sociodramática durante a formação médica}

O presente estudo não desconsidera os benefícios das diversas abordagens grupais desenvolvidas com estudantes de Medicina. Entretanto, como referencial teórico que subsidiou este trabalho, apresentaremos uma abordagem que, à semelhança de outros estudos, enfatiza a importância do contexto grupal, além de proporcionar uma vivência acerca do desenvolvimento de um papel.

Na evolução histórica acerca das práticas grupais, encontramos na teoria sociodramática de Moreno um método que enfatiza as relações interpessoais que ocorrem entre os indivíduos pertencentes a determinados contextos institucionais. O sociodrama, na concepção moreniana, é definido como um método de ação que trata das relações intergrupais e ideologias coletivas $^{12-16}$.

O objetivo principal da abordagem é a catarse social, é a mudança de atitudes, de princípios conservadores, do produto de papéis assumidos cultural e socialmente, a posturas mais críticas e reflexivas sobre estes papéis. O sociodrama parte dos conflitos sociais, tais quais objetivados enquanto eventos reais, e convida cada um de seus agentes potenciais a vivê-los na própria pele ${ }^{12,15}$.

Dessa forma, nos referimos ao sociodrama educacional, que pode também ser chamado de método educacional psicodramático, como um procedimento vivencial voltado para o grupo como um todo, sendo utilizado com o objetivo de investigação social e transformação de conflitos intergrupais ${ }^{12-15}$.

O emprego do sociodrama tem ocorrido nas áreas tanto da saúde como da educação e, independentemente do campo de atuação, a questão central destacada consiste na exteriorização do que se oculta nas relações e faz adoecer o social, buscando, assim, respostas mais saudáveis para os conflitos sociais ${ }^{17}$. Dessa forma, os conflitos são trazidos no grupo, são recriados, encenados e "vividos". Nesse sentido, os participantes atuam nesse es- paço que pode ser considerado pedagógico e profilático, onde todos colocam sua subjetividade num jogo de interação microssocial bastante próximo da realidade ${ }^{16}$.

Como salientado, o sociodrama educacional, ao ser definido como um método de ação que trata das relações intergrupais e ideologias coletivas ${ }^{15}$, utiliza técnicas psicodramáticas aplicadas a contextos educacionais, como, por exemplo, o role-playing. Esta técnica é utilizada no cenário da aprendizagem da prática médica, como no ensino de habilidades de comunicação com os pacientes, e nesse sentido, se torna uma ferramenta educacional importante para ofeedback desse aprendizado ou como instrumento educacional, auxiliando na construção de habilidades e atitudes condizentes com a prática médica ${ }^{18,19}$.

O sociodrama educacional, enquanto uma abordagem teórico-metodológica, caracteriza-se como uma linha de pesquisa-ação em Psicologia Educacional, num enfoque institucional que se propõe estudar as relações humanas nesse contexto. Utiliza estratégias de pesquisa qualitativa, buscando a investigação e a intervenção nesses contextos educacionais, a compreensão das interações sociais que constituem o cotidiano das instituições, enfocadas a partir das representações de papéis segundo os quais os diferentes integrantes da instituição pautam suas relações ${ }^{12,18}$.

Quanto à utilização das técnicas sociodramáticas no contexto da formação médica, são discutidas as vantagens do método nos vários contextos acadêmicos, desde o papel do "ser médico" à relação médico-paciente; a possibilidade de estabelecer um diagnóstico institucional e propostas profiláticas frente à inadaptação identificada por parte dos estudantes em relação à faculdade, proporcionando o rompimento de reputações cristalizadas e/ou estigmatizantes atribuídas pelo grupo a determinada pessoa; permite o aprendizado do trabalho em grupo; e a explicitação dos conflitos de papéis por meio de role-playing ${ }^{17}$.

Abordando o sociodrama aplicado à educação médica, apontamos sua pertinência quando as angústias manifestadas pelos estudantes têm a ver com o conflito de papéis existentes, de um lado, por parte do indivíduo, que já traz consigo uma história de crenças, atitudes e valores e, do outro, por parte do contexto institucional, com suas tradições, sua história, suas características peculiares; e, por fim, com as expectativas sociais que o papel profissional de médico venha a representar. Assim, proporcionar aos estudantes de Medicina um espaço para vivências, focalizadas no contato grupal e apoiadas pelo referencial sociodramático, pode favorecer a melhoria dos vínculos nas relações interpessoais e facilitar uma visão mais realista, mais crítica e reflexiva do médico internalizado em cada um. 
O presente estudo tem por objetivo investigar os efeitos de uma atividade prática reflexiva fundamentada no sociodrama educacional junto a estudantes de Medicina.

\section{METODOLOGIA}

O estudo foi delineado em quatro etapas:

1. Pré-inquérito: aplicação de questionário estruturado aos estudantes de Medicina de primeiro a terceiro ano de uma universidade pública do interior do Estado de São Paulo, para investigar seu nível de satisfação quanto ao curso;

2. Entrevista em grupos focais: da fase anterior foram selecionados 24 alunos que se dispuseram voluntariamente a participar desta fase, em que foram discutidos temas ligados às motivações da escolha profissional e dificuldades vivenciadas até o momento da formação;

3. Grupo reflexivo;

4. Avaliação sobre a atividade prático-reflexiva.

Neste trabalho apresentamos os resultados obtidos na terceira e quarta etapas do estudo.

\section{Participantes do estudo}

Os estudantes que aceitaram participar da atividade de grupo reflexivo foram originados dos grupos focais desenvolvidos na segunda etapa. Ficaram representados por dez estudantes de Medicina do segundo ao quarto ano, com idades de 18 a 23 anos, sendo 7 participantes do sexo feminino e 3 do sexo masculino.

\section{Coleta de dados}

Os dez alunos selecionados preliminarmente foram informados dos objetivos e dos procedimentos da atividade e tomaram ciência mediante os Esclarecimentos aos Participantes do Estudo, como previsto na Resolução 196/96. Foram informados de que participariam de nove reuniões semanais e que a décima ocorreria 15 dias após, para avaliar o processo vivenciado Dessa maneira, o grupo reflexivo ocorreu semanalmente, com duração de duas horas para cada reunião. A atividade ocorreu em horários predefinidos pelos alunos e que não coincidiam com o horário de aula (hora do almoço). Todas as reuniões de grupo reflexivo foram gravadas e transcritas.

\section{Análise dos dados}

No trabalho com grupos, torna-se inerente a construção e a análise do processo grupal, para identificar as redes sociométricas que se formam durante a atividade. Sendo assim, a leitura sociométrica de uma reunião de grupo ocorre levando em conta algumas peculiaridades e características do modelo em questão, considerando que todo grupo é uma sequência de movimentos e etapas e, além disso, todo processo grupal tem uma singularidade que deve e precisa ser respeitada. Tornar possível uma análise do processo grupal é, de certa forma, tornar visíveis esses movimentos do grupo e, dentro de cada momento, identificar as estruturas criadas.

O quadro 1 apresenta a proposta de um modelo de análise utilizado em estudos de natureza educacional e institucional, desenvolvido, ampliado e adaptado pelo Grupo de Estudos e Pesquisas Subjetividade e Educação (GEPSEd), construído a partir de conceitos teóricos originados do psicodrama e que foi adotado na análise dos nossos dados ${ }^{12,15,20}$.

Na sequência do modelo apresentado, a partir do momento em que é iniciada a reunião, já começam a ocorrer as composições, as junções e a sociometria. Dessas interações vão surgindo os projetos, definidos aqui como propostas que nascem da intersubjetividade promovida entre os membros, provocada pelas atividades de aquecimento.

A partir dos projetos que vão surgindo, os integrantes do grupo vão formando unidades sociométricas e assumem posições nesse contexto. Pode haver uma adesão expressa ao projeto - os participantes falam sobre o que pensam e sentem a respeito do projeto definido -, e também podem surgir unidades que se mostrem indiferentes ou que, mediante expressões não-verbais, manifestem algum desacordo ou indiferença quanto ao projeto.

O moderador grupal vai, assim, respeitando o surgimento dos projetos. A partir deles, vão surgindo as unidades sociométricas, ou seja, os agrupamentos de pessoas dentro do grupo que assumem posições frente aos projetos "anunciados". A formação das unidades ocorre por meio de uma configuração espontânea.

\section{RESULTADOS}

\section{A atividade grupal}

Os alunos que participaram da atividade reflexiva formaram um grupo relativamente heterogêneo, do segundo, terceiro e quarto anos de Medicina, e nesse aspecto era necessário que as primeiras reuniões pudessem favorecer a integração entre os membros. Os objetivos do trabalho foram reapresentados, já que tinham sido anunciados nas etapas anteriores do estudo (pré-inquérito e grupos focais). O quadro 2 indica a evolução do processo grupal desenvolvido, identificando as etapas, atividades sugeridas, número de projetos e principais temas abordados.

As três primeiras reuniões tiveram como objetivo central a construção de um contexto grupal e relacional positivo. Para isso, a equipe diretora recorreu a jogos dramáticos como atividade de aquecimento, pois no início da atividade o grupo ainda não se manifesta com uma sociometria bem definida. 
Quadro 1

Representação de um modelo de análise do processo grupal desenvolvido com estudantes de Medicina

\section{1 - ABERTURA}

Etapa desenvolvida pelos moderadores do grupo com o objetivo de realizar atividades de aquecimento (jogos dramáticos) como um procedimento sociométrico que auxilia na integração entre os membros.

\section{2 - PROJETO}

O projeto resulta do desejo expresso (ou pelo moderador ou por algum membro do grupo) que foi considerado por todos, ou no sentido de aceitação ou de oposição. Os projetos começam a se configurar após a abertura da reunião.

\section{3 - PROPOSTA}

A forma como os membros do grupo se posicionam em relação ao projeto.

4 - POSIÇÃO

A forma como os membros do grupo se posicionam em relação à proposta do projeto.

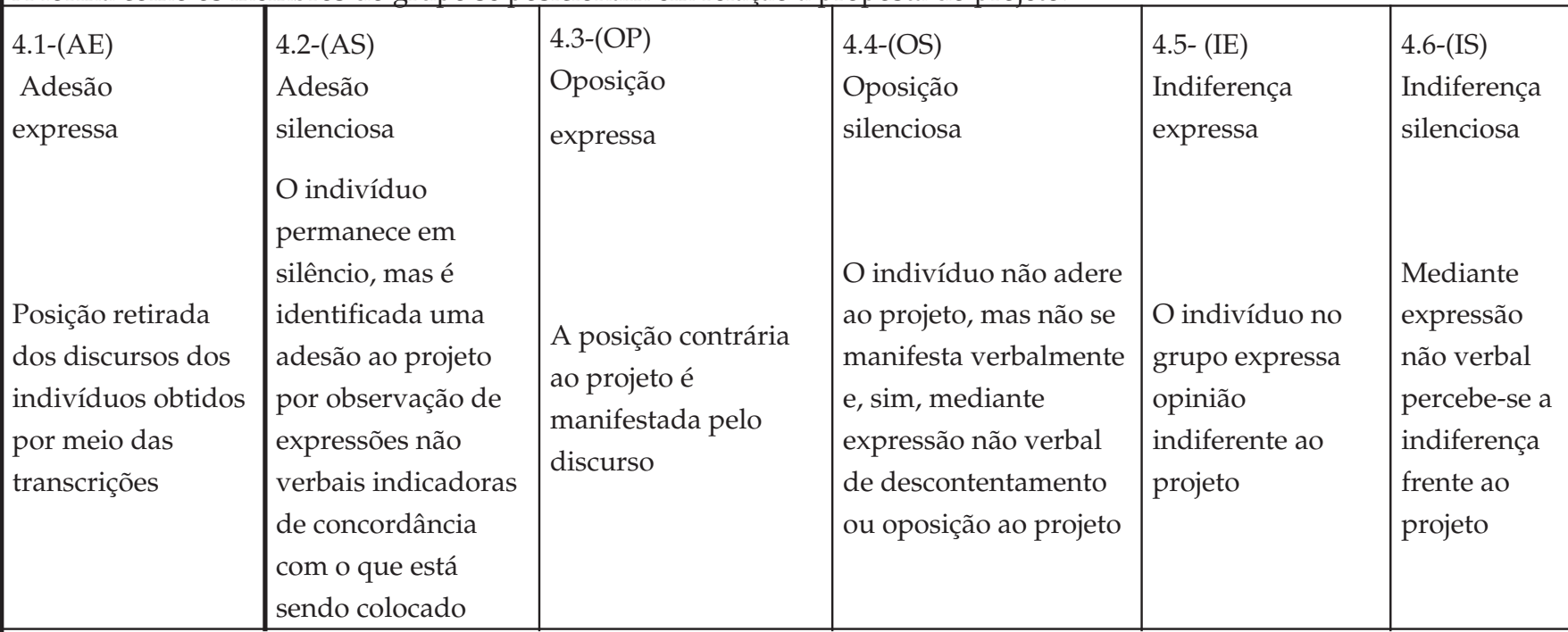

\section{5 - UNIDADES SOCIOMÉTRICAS}

Correspondem à posição que o indivíduo assume no plano coletivo, depois que o projeto é aceito pelo grupo. Dessa forma, para identificar as unidades é necessário:

a) Integrantes: quais os membros do grupo que compõem a unidade.

b) Posição em relação ao projeto (AE, AS, OP, OS, IE, IS).

c) Formas de manifestação: são retiradas da transcrição da sessão e expressam os temas que surgiram após a adesão ou não ao projeto.

Sendo assim, à medida que os jogos dramáticos iam sendo propostos, o grupo ia aderindo ao projeto da equipe diretora e iam sendo identificados alguns projetos. Os alunos discutiam a questão dos rótulos atribuídos aos colegas dentro da faculdade. Parece existir entre os alunos uma necessidade de falar a respeito do quanto os rótulos, ou seja, a visão estereotipada dos grupos prejudica a formação de relações interpessoais positivas.
Na sequência das reuniões iniciais, os projetos surgidos iam evidenciando os conflitos existentes nos primeiros anos da formação médica e o quanto existia a interferência das questões apontadas frente aos rótulos. Parece existir, na percepção dos alunos, uma necessidade de "ter que pensar igual" no início da vida acadêmica, o que promove uma grande homogeneidade na população de estudantes de Medicina. As reflexões giram em torno das consequências que esses sentimentos podem gerar 
Quadro 2

Evolução do processo grupal de uma atividade reflexiva junto a estudantes de Medicina

\begin{tabular}{|c|c|c|c|c|}
\hline \multicolumn{5}{|c|}{ Da Primeira à Terceira Reunião: Construção do Contexto Grupal } \\
\hline $3^{\underline{a}}$ & $\begin{array}{l}\mathrm{A} 1, \mathrm{~A} 2, \mathrm{~A} 3, \\
\mathrm{~A} 4, \mathrm{~A} 5, \mathrm{~A} 6, \\
\mathrm{~A} 7, \mathrm{~A} 8, \mathrm{~A} 9\end{array}$ & $\begin{array}{l}\text { Aquecimento: falar sobre } \\
\text { as qualidades e manias de } \\
\text { cada um } \\
\text { Aquecimento: falar de suas } \\
\text { preferências de carro, } \\
\text { música e esporte } \\
\text { Dinâmica sugerida: os } \\
\text { alunos simularam a } \\
\text { discussão de um caso } \\
\text { clínico, dando suas } \\
\text { opiniões, mas o grupo } \\
\text { tinha que reagir às } \\
\text { opiniões emitidas de } \\
\text { acordo com os rótulos } \\
\text { previamente colocados na } \\
\text { testa de cada um }\end{array}$ & 04 & $\begin{array}{l}\text { - O grupo adere aos objetivos do trabalho e participa da } \\
\text { atividade (jogo dramático). } \\
\text { - Inicia o tema "A formação dos rótulos nas relações } \\
\text { interpessoais dentro da Faculdade" } \\
\text { - Aderir e participar da atividade lúdica de aquecimento } \\
\text { - Continuação do projeto da reunião anterior: rótulos e } \\
\text { preconceitos na formação médica } \\
\text { - A formação de "panelas" no curso médico } \\
\text { - A trajetória no curso médico } \\
\text { - A medicina e outros cursos } \\
\text { - Aderir e participar da atividade lúdica de aquecimento } \\
\text { - Falar dos sentimentos vividos durante a atividade } \\
\text { - Sentimentos vividos no curso médico em relação aos } \\
\text { rótulos e estereótipos } \\
\text { - Necessidade de os estudantes de quarto ano } \\
\text { compartilharem dificuldades com os "mais novos" } \\
\text { - Interferência dos rótulos na construção positiva das } \\
\text { relações interpessoais entre alunos de anos diferentes }\end{array}$ \\
\hline \multicolumn{5}{|c|}{ Quarta à Sétima Reunião: Atividade Reflexiva - A Reflexão Individual Desenvolvida em um Contexto Grupal } \\
\hline
\end{tabular}


Quadro 2

Evolução do processo grupal de uma atividade reflexiva junto a estudantes de Medicina

\begin{tabular}{|c|c|c|c|c|}
\hline Reunião & Participantes & Atividade Sugerida & $\begin{array}{l}\text { № de } \\
\text { Projetos }\end{array}$ & Principais Temas Emergentes dos Projetos \\
\hline $7^{\mathrm{a}}$ & $\begin{array}{l}\text { A1, A2, A3, } \\
\text { A4, A6, A7, } \\
\text { A8, A9 }\end{array}$ & $\begin{array}{l}\text { Aquecimento: foi realizada } \\
\text { "uma viagem imaginária a } \\
\text { um planeta perfeito para o } \\
\text { médico", desenvolvida } \\
\text { com música, propondo aos } \\
\text { alunos que se imaginassem } \\
\text { nesse planeta e } \\
\text { estimulando-os a discutir o } \\
\text { tema } \\
\text { Atividade livre: não foi } \\
\text { proposta nenhuma } \\
\text { atividade dirigida, para } \\
\text { que o grupo pudesse falar } \\
\text { sobre os temas levantados } \\
\text { na reunião anterior }\end{array}$ & 11 & $\begin{array}{l}\text { - Atividade de aquecimento: "viagem a um planeta } \\
\text { perfeito para ser médico" } \\
\text { - Formação de subgrupos para discutir o mundo perfeito } \\
\text { do médico na fantasia } \\
\text { - Expressão dos sentimentos vividos durante a atividade } \\
\text { - Esclarecimento e reflexão sobre opiniões divergentes } \\
\text { dentro do grupo } \\
\text { - Falar sobre a visão de que não existe o mundo ideal para } \\
\text { o médico } \\
\text { - Frustração do trabalho médico e impotência médica } \\
\text { - Choque existente entre o mundo ideal e o mundo real } \\
\text { do médico } \\
\text { - Dificuldades ao lidar com a morte no curso médico } \\
\text { - Retomada dos questionamentos da reunião anterior a } \\
\text { respeito do planeta ideal para o médico } \\
\text { - Falar sobre a vida do estudante de Medicina e o } \\
\text { percurso realizado durante a vivência desse papel } \\
\text { - Discussão sobre a necessidade de espaços reflexivos } \\
\text { para os alunos. Ex.: Programas de Tutoria }\end{array}$ \\
\hline
\end{tabular}

para a futura prática médica, pois o desdobramento disso pode ser um distanciamento futuro na relação com o paciente e o "enraizar" de uma postura de que o médico é o único detentor do saber. Os alunos do quarto ano "sugerem" aos mais novos a importância do ciclo básico e a necessidade que o calouro tem de aprender a administrar melhor seu tempo, para que esse aprendizado possa ocorrer de maneira mais positiva.

A partir da quarta reunião, foi iniciado um processo reflexivo mais voltado à vida acadêmica como um todo. Na atividade de aquecimento proposta, o grupo entraria em contato com "cenas" do filme de sua vida acadêmica. O grupo foi orientado quanto à dinâmica escolhida e, ao final dela, pediu-se que todos escrevessem frases-rótulos que representassem sentimentos vividos em algum momento de sua formação acadêmica.

Essa atividade promoveu uma reflexão dos alunos frente a algumas particularidades que os estudantes de Medicina viven- ciam ao longo de suas vidas. Quanto à visão positiva, o grupo destacou que, a partir do segundo ano, vão se constituindo entre eles grupos mais sólidos e, à medida que vai evoluindo, o curso vai saindo da conotação de "só estudar" para outro nível, que é o de participar das Ligas, das atividades extracurriculares. No quarto ano, a noção da "responsabilidade de ser médico" começa a surgir, no acompanhamento de casos clínicos, de atividades práticas no hospital, e as responsabilidades vão aumentando, assim como a influência da faculdade na vida do aluno.

No entanto, ao considerarem os aspectos negativos que permeiam toda essa vivência, os alunos destacam os sentimentos ruins sobre o que é ser aluno de primeiro ano, pois o contexto desse momento da formação é muito representado por um excesso de aprendizado, por muitas mudanças e por uma "autonomia recém-conquistada". É destacado o sentimento de "frustração" com o curso e, de certa forma, parece que a passagem pelo ciclo básico "amortece" a idealização que os alunos tinham sobre o "ser médico". 
Nesse momento do grupo, percebe-se uma sintonia na sociometria grupal, pois as unidades formadas e que se manifestam a respeito compartilham seus sentimentos em relação à trajetória do curso e o quanto, durante esses períodos, o aluno se vê no meio de uma série de contradições e controvérsias frente a seus sentimentos pela futura profissão. As consequências ruins apontadas pelos alunos se relacionam com o fato também de que, apesar de viverem intensamente as atividades da faculdade, isto de certa forma os coloca "por fora" do mundo, pois o curso exige uma dedicação grande, e o aluno acaba permanecendo nesse espaço acadêmico a maior parte do tempo.

Na quinta reunião, o contexto que a originou continuou derivado das questões relacionadas ao curso médico e dos projetos das reuniões anteriores. Assim, nesse momento, o grupo foi convidado a desenvolver uma atividade de aquecimento que seria a de associar o que para cada um era "ser médico" a um símbolo. Os projetos surgidos após essa questão se relacionam a como o grupo percebe esse "ser médico" internalizado em cada um. Fica evidenciado na reflexão que se segue que esses sentimentos vão se modificando e amadurecendo durante os diferentes anos da graduação. Nos primeiros anos, "o ser médico" é repleto de uma representação que está associada a muito estudo, a muito cansaço, a muita pesquisa. A visão de médico nesse momento da formação é tida como uma desilusão, pois é como se estivessem vivendo num contexto muito fora da realidade idealizada por eles em relação à medicina.

O grupo reconhece que a atividade de aquecimento sobre o "ser médico" indicou pontos de vista diferentes entre eles frente ao idealizado e imaginado do médico, mas percebem que, apesar de tudo isso ser representado por cada um de forma diferente, existem aspectos comuns entre os membros do grupo. Consideramos aqui o quanto o grupo evoluiu em relação à representação inicial, quando nas primeiras reuniões não era ainda possível identificar pontos comuns entre eles.

De certa forma, uma das leituras desse modelo de análise sociométrica é perceber o quanto o grupo está conseguindo ser autogestivo. O diretor aqui se vê numa posição de facilitador desse processo. Inicialmente, ele dirige o grupo em toda a atividade de abertura, sugerindo as atividades de aquecimento, para que o processo grupal possa acontecer de maneira mais ágil, mas, a partir daí, o grupo é que decide se aceita ou não aderir aos projetos.

A reflexão permanece ainda no plano verbal, abordando a realidade tal como ela se dá no cotidiano. Este fato, em geral, inibe o processo reflexivo, pois aprisiona a reflexão nos valores que a realidade impõe. No contexto teórico do psicodrama pedagógico, recorre-se ao plano da fantasia como uma forma de liberar a reflexão dos participantes. Daí, termos optado por sugerir ao grupo, na sexta reunião, uma atividade em que eles trabalhariam exclusivamente no plano da fantasia. Esperávamos também que esta reflexão pudesse "aquecê-los" para, em seguida, completarmos o role-playing ou a dramatização do papel de aluno do curso médico.

Nesta reunião, portanto, foi sugerido aos alunos entrarem no plano da fantasia e trazerem para a reflexão em primeira pessoa os temas originados dessa vivência. Dessa forma, foi sugerida, como atividade de aquecimento, uma fantasia que se resumia a uma viagem a um planeta perfeito para o médico. O grupo trabalhou inicialmente em duplas. A maioria dos alunos identificou coisas positivas nesse mundo perfeito do médico, como, por exemplo, que havia doenças, mas estas não eram impeditivas de vida e que o médico desse mundo ideal valorizava o aspecto biopsicossocial do paciente.

No contexto grupal, entretanto, vão surgindo posicionamentos diferentes, evidenciando sentimentos bons e ruins durante a fantasia. Conforme indica o quadro 2, nesta reunião, ocorreram 11 projetos, indicando a organização de várias unidades sociométricas. Isto pode indicar que os participantes se sentiam à vontade para expressar suas divergências no contexto grupal e que o espaço ali construído, mediado pela equipe diretora, permitiu a todos "anunciar suas idéias", mesmo que divergentes uns dos outros. Assim, todos aderiram ao projeto de falar sobre as divergências e, nesse sentido, as unidades que se formaram discutiram o que isto representava, ou seja, a repressão é uma forma de perceber as contradições do mundo médico ou as do próprio aluno - em outras palavras, o mundo perfeito do médico pode ter muita coisa boa, mas também tem um lado impotente, um lado que reprime e que deprime também.

O grupo percebeu as constatações existentes no possível choque entre os mundos ideal e real do médico, mostrando que dentro de cada um deles existe um médico idealizado, um mundo idealizado de médico, uma saúde idealizada, um paciente idealizado. O tema da morte nesse mundo ideal foi também discutido nessa ocasião. O grupo refletiu que a escolha da profissão médica pode estar relacionada ao desejo de lutar contra a morte e que talvez falte ainda uma conscientização dos médicos frente a essa questão.

\section{O role-playing}

Na evolução do processo reflexivo, percebe-se então o momento de levar o grupo, ou pelo menos estimulá-lo, a falar do papel do estudante de Medicina, da vivência desse papel e como ele se manifesta para o grupo. Assim, o objetivo principal da oitava reunião foi desenvolver a interpretação lúdica de papéis, o role -playing. A equipe diretora ia estimulando e aquecendo todos para a dramatização, pedindo sugestões de cenas que poderiam ser representadas nessa atividade e que de certa forma tivessem relação com o papel do estudante e sua trajetória na vida acadêmica. A atividade de dramatização foi organizada, e os alunos desenvolveram o role-pla- 
ying. O tema escolhido foi "o ingresso no curso médico". As etapas do role-playing estão descritas no Quadro 3.

Assim, na escolha das cenas, os participantes do grupo, após serem estimulados e aquecidos para a escolha dos papéis, pensaram em cenas e em personagens do seu cotidiano. Aatividade de role-playing representou não apenas um momento lúdico, mas a oportunidade de viverem "cenas" da vida do estudante de Medicina, como o próprio grupo a denominou. As cenas escolhidas representaram a entrada do aluno no curso médico, a vida do calouro, sua relação com o veterano, com a instituição, a família e a sociedade como um todo. De certa forma, o grupo considerou que a atividade de dramatização representou para todos a visualização, de um resumo da vida acadêmica.

Após a dramatização, conforme indicado no quadro 3, passou-se à etapa de reflexão dentro do papel. Cada um dos alunos pôde falar como se sentiu no papel de outra pessoa. $\mathrm{O}$ diretor teve a tarefa de estimular o grupo frente à reflexão na ação. Esse momento foi a oportunidade do grupo de vivenciar a "inversão de papéis" e entrar em contato com seus sentimentos quando se coloca no lugar do outro. Assim, no contexto dramático, foi possível "colocar-se no lugar do outro", do calouro, do veterano, da família do calouro e de pessoas da própria sociedade. Os exemplos a seguir dos discursos sobre a vivência de alguns dos papéis ilustram a atividade de reflexão por meio da inversão de papéis:

"Tia gorda" A1 ( $4^{\circ}$ ano)bom, eu vou falar da tia gorda, porque assim... porque estar com sintomas assim deve ser muito difícil, a pessoa sei lá... numa idade assim... que às vezes tem pressão alta, diabetes, dor nas costas, dor no joelho, pesada, então sempre tem assim... a pessoa lidar com os próprios pontos de vista, você sempre relaciona isso a umas coisas que não têm nada a ver, que é como fugisse da medicina, eu acho que do ponto do paciente a gente, como paciente, acho que procura uma explicação pras coisas e qualquer um que a gente achar que possa saber alguma coisa a gente vai perguntar.

"O calouro" A7 ( $2^{\mathrm{o}}$ ano)é totalmente confuso, tô acabando de entrar na faculdade, tô em São Paulo, vem um veterano e me pergunta se eu tô usando a boina... [risos] ...de repente vem a tia... o que eu tenho... diabetes, tá $124 \ldots$ eu nem sei quanto é a glicemia normal... [risos] ...aí vai saber, né... a minha mãe era a mais chata... ai, filhinha..ai, filhinha [e imita a mãe falando, todo mundo cai na risada].

"O veterano" A5 ( $4^{\circ}$ ano) a gente tem orgulho do lugar que entrou... tudo... assim... se é melhor ou não... realmente assim... eu acreditava que era o melhor lugar que eu tava... e angustia assim... a preocupação de que isso se perpetue com as novas gerações, na verdade, toda essa disciplinação é pra pessoa dar valor pra onde ela tá e pra instituição... pra poder valorizar o lugar, as tradições, e tudo que eu passei eu acho que ela também tem que passar [risos]... eu acho assim, como veterano, o que eu tentei sentir um pouco assim, que eu vejo muito nos meus veteranos, é isso de passar para as gerações mais novas as tradições e tudo, até as partes mais chatas.

Dessa forma, visualizamos nesse processo a manifestação de um sociodrama educacional, pois o grupo todo é protagonista na ação, todos vivem papéis contextualizados no cotidiano da vida acadêmica, na família, na sociedade. As cenas vividas representaram a manifestação de conflitos grupais que ocorrem no contexto acadêmico.

Assim, foi possível perceber o quanto algumas das representações iniciais, que surgiram nos grupos focais, a respeito da medicina, da formação médica e do próprio médico, foram retomadas no grupo reflexivo. Por meio desta estratégia, foi possível trabalhar com o grupo essas representações e conceitos cristalizados, proporcionando um direcionamento melhor e mais aprofundado no sentido da reflexão, ajudando o grupo a elucidar um pouco mais seus sentimentos e suas posições frente a uma diversidade de momentos que acompanha a trajetória do estudante de medicina.

Nesse sentido, podemos considerar que o role-playing permitiu ao grupo um posicionamento talvez menos defensivo em relação ao papel do médico, reconhecendo que este tem limites e que precisa existir também um cuidado com a "pessoa" do médico. Além disso, foram evidenciadas as reflexões que o grupo fez quanto à evolução de sua vida acadêmica, do desenvolvimento de seu papel profissional, que se configurou como um dos nossos objetivos principais.

\section{Avaliação do grupo reflexivo}

A reunião de avaliação foi proposta aos alunos para que ocorresse 15 dias após o término do grupo. Todos concordaram, e o grupo todo compareceu no dia marcado. Foi escolhida como estratégia de avaliação grupal a entrevista de grupo focal, que foi gravada e transcrita. Alguns temas foram selecionados para a avaliação:

1. Avaliação cognitiva: o que foi o grupo reflexivo para cada um dos participantes, como eles denominariam ou caracterizariam o processo que vivenciaram; 
Quadro 3

Etapas relacionadas à oitava e à nona reunião do grupo reflexivo: desenvolvimento de um role-playing com estudantes de Medicina

\begin{tabular}{|l|l|l|l|l|}
\hline Reunião & Participantes & $\begin{array}{l}\text { Atividade } \\
\text { Sugerida }\end{array}$ & $\begin{array}{l}\text { No de } \\
\text { Projetos }\end{array}$ & Principais Temas Emergentes dos Projetos \\
\hline $8^{\text {a }}$ & $\begin{array}{l}\text { A1, A2, A3, A4, } \\
\text { A5, A6, A7, A9 }\end{array}$ & $\begin{array}{l}\text { Ocorreu nesta reunião } \\
\text { o role playing }\end{array}$ & 07 & $\begin{array}{l}\text { - Foram retomados os temas da reunião passada } \\
\text { - Foi sugerida a organização de uma atividade lúdica } \\
\text { - Atividades de aquecimento para o role playing }\end{array}$ \\
\hline
\end{tabular}

Etapas do Role-Playing

a)Tema escolhido para a dramatização: "o ingresso no curso médico"

Temas escolhidos para as cenas:

1. O calouro de Medicina e as solicitações "médicas" (sociedade e família)

2. O calouro, a relação com o veterano e a instituição

b) A inversão de papéis (role-playing): a reflexão no papel escolhido: "como me sinto no papel do outro"

(família, sociedade, veterano)

c) A volta ao papel de estudante, os sentimentos e as reflexões sobre o "colocar-se no lugar do outro"

d) O sociodrama educacional: o grupo todo é o protagonista na ação

\begin{tabular}{|l|l|l|l|l|}
\hline Reunião & Participantes & \multicolumn{1}{c|}{$\begin{array}{c}\text { Atividade } \\
\text { Sugerida }\end{array}$} & $\begin{array}{c}\text { No de } \\
\text { Projetos }\end{array}$ & \multicolumn{1}{c|}{ Principais Temas Emergentes dos Projetos } \\
\hline $9^{\text {ạ }}$ & $\begin{array}{l}\text { Atividade livre: não foi } \\
\text { proposta nenhuma } \\
\text { A6, A7, A8, A9, } \\
\text { A10 }\end{array}$ & $\begin{array}{l}\text { Pedividade dirigida e foi } \\
\text { retomassem a reunião } \\
\text { anterior e falassem de } \\
\text { seus sentimentos a } \\
\text { respeito da vivência } \\
\text { com o role-playing }\end{array}$ & 11 & $\begin{array}{l}\text { - Retomar os principais momentos da reunião anterior } \\
\text { - Expressar os sentimentos frente à vivência do role-playing } \\
\text { - Discussão sobre as atitudes defensivas dos médicos } \\
\text { - Reflexão sobre a experiência de grupo vivenciada } \\
\text { - Retomada dos principais aspectos e temas abordados } \\
\text { durante o processo reflexivo } \\
\text { - Os questionamentos e o repensar o papel do aluno em } \\
\text { desenvolvimento. }\end{array}$ \\
\hline
\end{tabular}

2. Avaliação afetivo-vivencial: o que sentiu ao vivenciar o processo grupal, quais foram os seus sentimentos ao participarem do grupo;

3. Aproximação avaliativa: no geral, como avalia o grupo, como uma experiência positiva, negativa, o que faltou nas atividades e sugestões para futuros trabalhos

Desta forma, com base nos discursos dos alunos, pudemos "mapear" os temas emergentes frente aos tópicos sugeridos para a avaliação (cognitiva, afetiva e avaliativa). O Quadro 4 apresenta a descrição das categorias empíricas obtidas frente à avaliação geral da atividade reflexiva.

Assim, quando perguntado ao grupo que denominação daria ao processo vivido, os estudantes, em sua maioria, definiram o grupo como um espaço para reflexão a respeito da vida do estudante de Medicina ou como um grupo de discussão a respeito da identidade médica em formação. Também foi apontado que o grupo significou um espaço para trocas, apoio, aprendizado e, acima de tudo, uma experiência que favoreceu um questionamento sobre como organizar as idéias e pensamentos que advêm da experiência acadêmica. Um aluno sustentou que o exercício de "se colocar no lugar do outro" permitiu organizar seus pensamentos e aprender a lidar com a perspectiva do outro. Nesse sentido, o grupo acabou por favorecer o compartilhar de sentimentos, bem como elucidar em algumas ocasiões os conflitos que surgem frente à trajetória acadêmica.

O conceito que ficou para os alunos sobre o grupo foi homogêneo e congruente entre os participantes, indicando que a ativi- 
Quadro 4

Categorias empíricas obtidas da reunião de avaliação do grupo reflexivo

\begin{tabular}{|c|c|}
\hline Temas & Categorias Empíricas Levantadas \\
\hline $\begin{array}{l}3 \text { - Aproximação avaliativa: avaliação geral das atividades } \\
\text { e sugestões }\end{array}$ & $\begin{array}{l}\text { 3.2) Aproximar mais os alunos de profissionais } \\
\text { recém-formados } \\
\text { 3.3) A importância da reflexão, mas ao mesmo tempo o } \\
\text { reconhecimento do quanto é difícil transpor barreiras para } \\
\text { externar sentimentos }\end{array}$ \\
\hline
\end{tabular}


dade proposta atingiu os objetivos pretendidos inicialmente, conforme indicam a seguir os exemplos de alguns discursos dos alunos sobre o tema.

Na sequência da entrevista de grupo focal, foi perguntado aos alunos como foi para eles a participação do ponto de vista afetivo. A intenção ao avaliar esse aspecto era verificar o nível de investimento afetivo que o grupo considerou quando de sua participação numa atividade nova, diferente das atividades acadêmicas desenvolvidas até então.

Conforme indicado no Quadro 4, os alunos apontaram que participar da atividade foi "divertido", mas também representou para a maioria sentimentos de compartilhar angústias e ansiedades que antes eram vividos solitariamente. $\mathrm{O}$ grupo levantou que alguns dos sentimentos vivenciados durante o ciclo básico não eram divididos com colegas ou pessoas mais próximas, em face da representação que tinham de que aquele sentimento ou dificuldade era sentida apenas por eles. No grupo, foi possível perceber que a insegurança, as angústias e os medos são compartilhados por alunos de outros anos e que é possível ocorrer a troca desses sentimentos de maneira construtiva. Os alunos de anos mais recentes consideraram oportuna a troca com os alunos de anos mais avançados, e estes últimos puderam se sentir valorizados por "ajudar" seus colegas a lidar melhor com as dificuldades que eles já enfrentaram. Além disso, participar do grupo reflexivo também foi considerada uma experiência de "relaxamento" e de "alívio das angústias" relacionadas à formação médica.

O discurso a seguir exemplifica o sentimento frente a esse tópico da avaliação:

[...] acho que o balanço geral foi muito mais positivo do que negativo; eu diria que eu nem tive sentimento negativo, não, não que eu lembro... minha avaliação é muito positiva, eu gostei muito de ter participado disso mesmo, os horários de almoço que eu perdi, o tempo que foi corrido, eu acho que valeu muito mais a pena aquilo que eu aprendi, aquilo que eu vivenciei, aquilo que eu compartilhei do que o tempo que eu poderia ter ficado descansando ou qualquer outra coisa; foi uma coisa que eu acho que se eu pudesse eu faria com que todo mundo participasse também... e eu vejo, conversando com todo mundo assim, seja numa rodinha de bar, seja no bandejão, seja em qualquer outro lugar, eu vejo que as pessoas passam pelas mesmas coisas que eu passei,mas na maioria das vezes a gente não põe isso daí pra fora, não põe tudo pra fora... e aqui eu senti que foi uma oportunidade de colocar mesmo tudo pra fora... falar aquilo que tá passando é interessante porque quando a gente toca nesse assunto direto surgem coisas que a gente tava passando, mas não sabia, não tinha percebido que tava passando por isso... não digo esse grupo, mas continuar esse trabalho, e mesmo aquilo que você falou, de fazer aquele trabalho com o primeiro ano eu acho muito interessante; eu tive no primeiro ano acho que foi um dia só, uma tarde, alguma coisa assim que foi uma, a minha turma se dividiu em grupos de dez, aí eu lembro que tinha alguns veteranos, uns dois ou três e um professor,mas foi num dia que eu ainda nem tinha tido aula, então, eu não sabia aquilo que eu ia passar pela faculdade[...]. (A10)

Na sequência do processo de avaliação, foi perguntado ao grupo como avaliaria, no geral, a atividade vivenciada. Além disso, foi dada a oportunidade aos alunos de fazerem sugestões sobre a experiência vivida.

Para os estudantes, a avaliação geral do grupo foi bastante positiva. È importante observar que os alunos de Medicina não vivem com frequência a experiência de trabalhos grupais. Foi possível observar suas dúvidas sobre a maneira como tinham que se "comportar" durante tais atividades. A falta de experiência e até mesmo da vivência de trabalho grupal, representada em uma atividade reflexiva, desperta curiosidade e promove questionamentos, pois a representação dos modelos de grupos que os estudantes possuem está muito relacionada aos modelos terapêuticos.

Outro aspecto importante observado em relação aos benefícios do grupo reflexivo foi a possibilidade de "quebra dos estereótipos" existentes frente às situações que possam envolver calouros e veteranos. O relacionamento entre eles pode ser produtivo e rico em termos de trocas, contribuindo para a quebra de possíveis "rótulos" que são construídos à medida que o curso evolui. Dessa maneira, é possível ocorrer uma compreensão melhor ou até mesmo mudanças nas representações iniciais dos alunos frente a estes aspectos abordados.

Apesar disso, na maioria dos discursos dos estudantes observa-se a necessidade e a sugestão de que se dê continuidade a iniciativas dessa natureza. A atividade possibilitou aprofundar mais as representações inicialmente abordadas nos grupos focais sobre a profissão médica, sua trajetória e o reflexo disso no desenvolvimento do papel de aluno e na construção de sua identidade profissional. O processo reflexivo trouxe contribuições enquanto um "espaço" para compartilhar sentimentos e também evidenciou a necessidade e a importância do desenvolvimento e análise científica de estudos que adotem como instrumental teórico a pesquisa-intervenção. 


\section{CONCLUSÕES E IMPLICAÇÕES EDUCACIONAIS}

O grupo reflexivo sociodramático teve como objetivo central trabalhar os conflitos acadêmicos dos estudantes de Medicina, considerando que esses problemas enfrentados no decorrer da formação médica não podem ser analisados isoladamente. Eles estão inseridos num contexto que tem por um lado o aluno, sua história e crenças pessoais, e, por outro, a instituição educacional, também com sua cultura, sua história, além de toda a sociedade, com conceitos cristalizados e estereótipos construídos acerca da profissão médica. Assim, o role-playing representou um modo de resgate da espontaneidade e buscou, de certa forma, o desenvolvimento de um "grupo em fusão", que seria o que se constitui numa relação de interioridade ${ }^{11,20}$.

Entendemos que a prática reflexiva, ancorada em referenciais que permitam a expressão da espontaneidade, pode promover mudanças nas representações que os indivíduos possuem sobre seus papéis sociais vividos em contextos educacionais. No entanto, sabemos o quanto pode ser difícil a mudança brusca, o rompimento de conceitos cristalizados, enraizados nos indivíduos e, muitas vezes, reforçados pela sociedade. Acreditamos que mediante a atividade reflexiva desenvolvida com os estudantes de Medicina pudemos iniciar, com este estudo, um processo de sensibilização para modelos de estratégias dessa natureza, que visem a um melhor amadurecimento e reflexão crítica sobre o desenvolvimento do papel profissional do futuro médico.

Assim, a nosso ver, do presente estudo podemos retirar as seguintes sugestões e implicações educacionais:

- Instituir e aprimorar atividades formativas reflexivas no ensino de graduação que visem, sobretudo, promover um contato maior entre os alunos ingressantes no curso médico com seus professores e/ou médicos, assim como com os veteranos;

- Considerar a importância fundamental dos serviços de apoio ao estudante universitário na tarefa de auxiliar a instituição, mais especificamente os órgãos que se preocupam com o ensino de graduação.

O estudo aqui apresentado traz indicações, tendências, que, muito embora não possam ser generalizadas para um contexto maior, devido à limitação da amostra, trazem contribuições complementares a outros estudos já realizados que indicam dificuldades similares desse contexto acadêmico. Acreditamos numa "parceria" entre a instituição, os serviços de apoio e seus órgãos colegiados responsáveis pelo ensino de graduação que possa levar ao aperfeiçoamento almejado por todos para o curso médico.

\section{REFERÊNCIAS}

1. Mercuri E, Polydoro SAJ. Estudante universitário: características e experiências de formação. [s.1.]: Cabral Editora; 2004.

2. Joly MCRA, Santos AAA, Sisto FF. Questões do cotidiano universitário. São Paulo: Casa do Psicólogo; 2005.

3. Marins JJN, Rego S, Lampert JB, Araújo JGC. (Org.). Educação Médica em transformação: instrumentos para a construção de novas realidades. São Paulo: Hucitec; 2004.

4. Feuerwerker LCM. Gestão dos processosde mudanças na graduação em medicina. In: Marins JJN, Rego S, Lampert JB, Araújo JGC. (Org.) Educação Médica em transformação: instrumentos para a construção de novas realidades. São Paulo: Hucitec; 2004. p.17-39.

5. Osório LC. Grupos. Teorias e Práticas. Acessando a era da grupalidade. Porto Alegre: Artmed; 2000.

6. Zimerman DE, Osório LC. (Org.). Como trabalhamos com grupos. Porto Alegre: Artmed; 1997.

7. Zanolli MB. Metodologias ativas de ensino-aprendizagem na área clínica. In: Marins JJN, Rego S, Lampert JB, Araújo JGC. (Org.). Educação Médica em transformação: instrumentos para a construção de novas realidades. São Paulo: Hucitec; 2004. p.40-61.

8. Missenard A et al. A experiência Balint: história e atualidade. Trad. Nelson da Silva Júnior. São Paulo: Casa do Psicólogo; 1994.

9. Coronel LCI. Grupos de reflexão. In: Zimerman DE, Osório LC (Org.). Como trabalhamos com grupos. Porto Alegre: Artmed; 1997. p.345-349.

10. Souza MCBM. Grupos realizados por enfermeiros na área de saúde mental. Esc Anna Nery. Revista Enfermagem. 2006;10(1):132-138.

11. Brandão J. Relação médico-doente: sua complexidade e papel dos grupos Balint. Revista Port. Clin Geral 2007;23:733-44.

12. Andrade AS. Intervenções grupais na educação. In: Fleury HJ, Marra MM. Sociodrama Educacional: uma estratégia de pesquisa-ação em psicologia escolar institucional. São Paulo: Agora; 2005. p.49-66.

13. Romana MA. Do psicodrama pedagógico à pedagogia do drama. Campinas, SP: Papirus; 1996.

14. Romana MA. Desenvolvendo um pensamento vivo mediante uma didática sócio psicodramática. Linhas Críticas. 1999;4(7-8). 
15. Andrade AS. Sociodrama Educacional: uma estratégia de pesquisa-ação em Psicologia Escolar institucional. Revista da SPAGESP. 2002;3:119-126.

16. Almeida CA. (Org.) Grupos. A proposta do Psicodrama. São Paulo: Agora; 1999.

17. Naffah Neto A. Psicodrama. Descolonizando o imaginário. Um ensaio sobre J. L. Moreno. São Paulo: Brasiliense; 1979

18. Jacobsen T, Baerheim A, Lepp MR, Schei E. Analysis of role-play in medical communication training using a theatrical device the fourth wall. Medical Education. 2006;6:51

19. Nestel D, Tierney T. Role-play for medical students learning about communication: guidelines for maximizing benefits. Medical Education. 2007;7:3.
20. Milan B. O jogo do esconderijo. Terapia em questão. São Paulo: Pioneira; 1976.

\section{CONFLITO DE INTERESSES}

Declarou não haver

\section{ENDEREÇO PARA CORRESPONDÊNCIA}

Maria de Fátima Aveiro Colares

Centro de Apoio Educacional e Psicológico

Faculdade de Medicina de Ribeirão Preto - USP

Av Bandeiranes, 3900

Ribeirão Preto - São Paulo

CEP: 14049-900

E-mail: fcolares@fmrp.usp.br 